\title{
Factors influencing agreement of breast cancer luminal molecular subtype by Ki67 labeling index between core needle biopsy and surgical resection specimens
}

\author{
Kristina A. Tendl-Schulz ${ }^{1}$ • Fabian Rössler ${ }^{2}$ • Philipp Wimmer ${ }^{1}$ • Ulrike M. Heber ${ }^{1}$ • Martina Mittlböck ${ }^{3}$. \\ Nicolas Kozakowski ${ }^{1} \cdot$ Katja Pinker $^{4,5} \cdot$ Rupert Bartsch $^{6}$ - Peter Dubsky ${ }^{7,8}$. Florian Fitzal ${ }^{7}$. Martin Filipits ${ }^{9}$. \\ Fanny Carolina Eckel ${ }^{7}$ • Eva-Maria Langthaler ${ }^{1}$ • Günther Steger ${ }^{6}$. Michael Gnant ${ }^{10}$. Christian F. Singer ${ }^{11}$. \\ Thomas H. Helbich ${ }^{4}$ - Zsuzsanna Bago-Horvath ${ }^{1}$
}

Received: 19 February 2020 / Revised: 20 March 2020 / Accepted: 16 April 2020 / Published online: 7 May 2020

(C) The Author(s) 2020

\begin{abstract}
Reliable determination of Ki67 labeling index (Ki67-LI) on core needle biopsy (CNB) is essential for determining breast cancer molecular subtype for therapy planning. However, studies on agreement between molecular subtype and Ki67-LI between CNB and surgical resection (SR) specimens are conflicting. The present study analyzed the influence of clinicopathological and sampling-associated factors on agreement. Molecular subtype was determined visually by Ki67-LI in 484 pairs of CNB and SR specimens of invasive estrogen receptor (ER)-positive, human epidermal growth factor (HER2)-negative breast cancer. Luminal B disease was defined by Ki67-LI > 20\% in SR. Correlation of molecular subtype agreement with age, menopausal status, CNB method, Breast Imaging Reporting and Data System imaging category, time between biopsies, type of surgery, and pathological tumor parameters was analyzed. Recurrence-free survival (RFS) and overall survival (OS) were analyzed using the Kaplan-Meier method. CNB had a sensitivity of $77.95 \%$ and a specificity of $80.97 \%$ for identifying luminal B tumors in CNB, compared with the final molecular subtype determination after surgery. The correlation of Ki67-LI between CNB and SR was moderate (ROC-AUC 0.8333). Specificity and sensitivity for CNB to correctly define molecular subtype of tumors according to SR were significantly associated with tumor grade, immunohistochemical progesterone receptor (PR) and p53 expression $(p<0.05)$. Agreement of molecular subtype did not significantly impact RFS and OS ( $p=0.22$ for both). The identified factors likely mirror intratumoral heterogeneity that might compromise obtaining a representative CNB. Our results challenge the robustness of a single CNB-driven measurement of Ki67-LI to identify luminal B breast cancer of low (G1) or intermediate (G2) grade.
\end{abstract}

Kristina A. Tendl-Schulz and Fabian Rössler contributed equally to this work.

Zsuzsanna Bago-Horvath

zsuzsanna.bago-horvath@meduniwien.ac.at

1 Department of Pathology and Comprehensive Cancer Center, Medical University of Vienna, 18-20 Waehringer Guertel, A-1090 Vienna, Austria

2 Department of Surgery and Transplantation, University Hospital and University of Zurich, Zurich, Switzerland

3 Center for Medical Statistics, Informatics, and Intelligent Systems, Section for Clinical Biometrics, Medical University of Vienna, Vienna, Austria

4 Department of Biomedical Imaging and Image-guided Therapy, Division of Molecular and Gender Imaging, Medical University of Vienna, Vienna, Austria
5 Department of Radiology, Breast Imaging Service, Memorial Sloan Kettering Cancer Center, New York, NY, USA

6 Department for Medicine I/Division of Oncology, Medical University of Vienna, Vienna, Austria

7 Department of Surgery and Breast Health Center, Comprehensive Cancer Center, Medical University of Vienna, Vienna, Austria

8 Hirslanden Klinik St. Anna Brustzentrum, Lucerne, Switzerland

9 Institute of Cancer Research and Comprehensive Cancer Center, Medical University Vienna, Vienna, Austria

10 Comprehensive Cancer Center, Medical University of Vienna, Vienna, Austria

11 Department of Obstetrics and Gynaecology and Breast Health Center, Comprehensive Cancer Center, Medical University of Vienna, Vienna, Austria 
Keywords Breast cancer $\cdot$ Luminal molecular subtype $\cdot$ Agreement $\cdot$ Core needle biopsy $\cdot$ Ki67

\section{Introduction}

Reliable determination of molecular subtype is indispensable for prognostication and treatment decision in breast cancer $(\mathrm{BC})[1,2]$. Especially in estrogen receptor (ER)positive and human epidermal growth factor 2 (HER2)negative luminal $\mathrm{BC}$, assessment of molecular subtype is of critical prognostic importance [3-9]. Current St. Gallen guidelines confirm the role of the proliferation marker Ki67 labeling index (Ki67-LI) in discriminating good prognosis "luminal A" (LumA) from "luminal B" (LumB) disease with less favorable prognosis [2]. In the absence of molecular assays, Ki67-LI still remains a main factor governing molecular subtype determination and (neo-)adjuvant treatment choice in early luminal-type BC $[1,10-14]$. However, reproducible and clinically valid Ki67-LI determination in core needle biopsy (CNB) might be biased by technical difficulties, assessment methods, or intratumoral heterogeneity. Exact measures of standardization such as a cutoff value or compensating for intratumoral heterogeneity remain elusive. Although digital image analysis seems a promising tool to facilitate robust and reliable determination of Ki67-LI, additional challenges still remain to be addressed [15, 16]. At present, no universal Ki67-LI cutoff levels to define molecular subtype in luminal $\mathrm{BC}$ are specified, and discrepancies regarding implications on clinical decisions persist $[1$, 17-19]. Whereas cutoff values can be statistically validated, the influence of intratumoral heterogeneity on the reliability of Ki67-LI in CNB remains to be resolved.

Recommendations to standardize Ki67-LI assessment recognized the need for further studies to evaluate comparability of Ki67-LI between CNB and whole tumor slides of surgical resection (SR) specimens [17]. We therefore evaluated the reliability of Ki67-LI to define molecular subtype by analyzing the concordance between CNB and SR specimens in 484 early untreated luminaltype $\mathrm{BC}$ patients. We investigated clinicopathological factors and possible sampling-associated confounders, such as CNB method and time between CNB and surgery that might impact the reliability of molecular subtype/Ki67-LI determination in CNB. Our results might help to improve the interpretation of CNB-derived measurements as prognostic indicators and outcome predictors in luminal $\mathrm{BC}$. The identification of factors that predict discrepancies between CNB and SR could aid the targeted implementation of molecular assays in luminal $\mathrm{BC}$ cases where reliable molecular subtype determination and neoadjuvant therapy indication require additional analyses.

\section{Patients and methods}

\section{Patients}

Patients $(n=484)$ with ER+/HER2- invasive BC at the Medical University of Vienna (MUW) were included in this retrospective analysis. Study procedures were approved by the Institutional Review Board of the MUW (1245/2017). Patients with primary operable luminal BC stages I-III who received diagnostic $\mathrm{CNB}$ and curative surgery without neoadjuvant therapy between 2010 and 2012 were eligible to participate. Age, menopausal status, type of surgery (breast conserving vs. mastectomy), and previous BC history were recorded for each patient. Clinical and pathological patient characteristics are described in Table 1. Follow-up data was available for $390(80.6 \%)$ patients. At a median follow-up of 62.6 months (ranged 1-105 months), 63 (16.2\%) patients had relapsed and 63 patients $(16.2 \%)$ had died.

\section{Radiology}

All patients underwent pre-operative either stereotactic vacuum-assisted (9G), ultrasound core needle (14G), or magnetic resonance imaging (MRI) vacuum-assisted (9G) guided breast biopsy according to the European Society of Breast Imaging (EUSOBI) guidelines [20]. In some patients, CNB was performed under no image guidance (palpation). Documented parameters included Breast Imaging Reporting and Data System (BI-RADS) assessment category of imagedetected lesions, CNB method, and surgery time interval (STI) between CNB and surgery (Table 1).

\section{Pathology and immunohistochemistry}

Workup was carried out according to the EU guidelines [21, 22] and the WHO classification [23]. Histopathological tumor grade $(\mathrm{G})[24,25]$, tumor size (pT), multifocality, lymph node $(\mathrm{pN})$ status, and presence of peritumoral lymphovascular invasion (LVI) were determined by two experienced pathologists (ML, ZBH). All cases were reviewed together; discrepant cases were discussed to reach consensus. All grading parameters (tubuloglandular differentiation, nuclear pleomorphy, and mitotic count) were recorded separately for $\mathrm{CNB}$ and SR, whereas measurements in SR were defined as gold standard.

Assessment of ER, progesterone receptor (PR), HER2, Ki67-LI, and p53 was performed using Ventana BenchMark Ultra (Ventana, Tucson, AR, USA) according to the ASCO/ USCAP guidelines [26, 27]. Ki67-LI was determined as 
Table 1 Patients' characteristics: data are presented as median (minimum-maximum) or as absolute frequencies (percentages)

\begin{tabular}{|c|c|}
\hline Clinicopathological parameters & $N(\%)$ \\
\hline \multicolumn{2}{|l|}{ Age (years) } \\
\hline Median (min-max) & $62.5(29.8-92.7)$ \\
\hline \multicolumn{2}{|l|}{ Menopausal status } \\
\hline Premenopausal/postmenopausal/unknown & $93(19.2 \%) / 379(78.3 \%) / 12(2.5 \%)$ \\
\hline \multicolumn{2}{|l|}{ Breast cancer history } \\
\hline No previous $\mathrm{BC} /$ recurrent $\mathrm{BC}$ & $432(89.3 \%) / 52(10.8 \%)$ \\
\hline \multicolumn{2}{|l|}{ CNB method } \\
\hline US-guided/stereotactic/MR-guided/palpatory & $389(80.4 \%) / 21(4.3 \%) / 50(10.3 \%) / 24(5.0 \%)$ \\
\hline \multicolumn{2}{|l|}{ BI-RADS assessment category } \\
\hline IV/V/unknown & $160(33.1 \%) / 258(58.9 \%) / 39(8.1 \%)$ \\
\hline \multicolumn{2}{|l|}{ Surgery time interval (STI, days) } \\
\hline Median (min-max) & $25.0(2-105)$ \\
\hline \multicolumn{2}{|l|}{ Type of surgery } \\
\hline Breast conserving surgery/mastectomy & $362(74.8 \%) / 122(25.2 \%)$ \\
\hline \multicolumn{2}{|l|}{ Tumor type } \\
\hline NST/lobular/mixed/other & $394(81.4 \%) / 70(14.5 \%) / 4(0.8 \%) / 16(3.3 \%)$ \\
\hline \multicolumn{2}{|l|}{ Grade } \\
\hline \multirow[t]{2}{*}{$\mathrm{G} 1 / \mathrm{G} 2 / \mathrm{G} 3 / \mathrm{GX}$} & CNB: $142(29.3 \%) / 247(51.1 \%) / 94(19.4 \%) / 1(0.2 \%)$ \\
\hline & SR: $117(24.2 \%) / 253(52.3 \%) / 114(23.6 \%) /---$ \\
\hline \multicolumn{2}{|l|}{ Molecular subtype } \\
\hline \multirow[t]{2}{*}{ LumA/LumB } & CNB: $207(42.8 \%) / 277(57.2 \%)$ \\
\hline & SR: $195(40.3 \%) / 289(59.7 \%)$ \\
\hline \multicolumn{2}{|l|}{ In situ (DCIS) component in CNB } \\
\hline Yes/no & $212(43.8 \%) / 272(56.2 \%)$ \\
\hline \multicolumn{2}{|l|}{ Tumor size } \\
\hline $\mathrm{pT} 1 / \mathrm{pT} 2 / \mathrm{pT} 3 / \mathrm{pT} 4$ & $338(69.8 \%) / 128(26.4 \%) / 14(2.9 \%) / 4(0.8 \%)$ \\
\hline \multicolumn{2}{|l|}{ Focality } \\
\hline Unifocal tumor/multifocal tumor/unknown & $364(75.2 \%) / 119(24.6 \%) / 1(0.2 \%)$ \\
\hline \multicolumn{2}{|l|}{ Lymph node status } \\
\hline $\mathrm{pN} 0 / \mathrm{pN} 1 \mathrm{a} / \mathrm{pN} 2 \mathrm{a} / \mathrm{pN} 3 \mathrm{a} / \mathrm{pNx}$ & $325(67.1 \%) / 100(20.7 \%) / 25(5.2 \%) / 18(3.7 \%) / 16(3.3 \%)$ \\
\hline \multicolumn{2}{|l|}{ Lymphovascular invasion } \\
\hline \multirow[t]{2}{*}{ Absent/mild/severe } & CNB: $465(96.1 \%) / 19(3.9 \%) /---$ \\
\hline & SR: $340(70.2 \%) / 138(28.5 \%) / 6(1.3 \%)$ \\
\hline
\end{tabular}

described previously [28]. The entire tumor area was evaluated by estimation, yielding an average Ki67-LI score. LumA molecular subtype was defined by a Ki67-LI of $<20 \%$. To enable comparability, \% scores of ER, PR, Ki67, and p53 were normalized to ten-percentile values. Accordingly, cases with Ki67-LI values between 10 and $14 \%$ were regarded as LumA disease, whereas the definition of luminal B breast cancer included cases with values between 15 and $20 \%$.

\section{Statistical analyses}

Continuous data are presented as median, minimum, and maximum due to skew distributions. Categorical data are presented as absolute frequencies and percentages.
Sensitivities to correctly predict LumB molecular subtype in SR and specificities to predict LumA molecular subtype by CNB are given partly together with $95 \%$ confidence intervals according to the method of Wilson. To assess diagnostic ability of CNB to predict SR over several CNB cut-points, a receiver operating characteristic (ROC) curve and its area under the curve are given.

Associations between two binary variables are tested by chi-square test or Fisher's exact test in case of small cell numbers. To test ordinal variables between LumA and LumB molecular subtype, a trend chi-square test was used and an exact version was used in case of small numbers. 
Recurrence-free survival was defined as the interval between the CNB and the first evidence of relapse at any site or incidence or contralateral breast cancer. Overall survival was defined as the interval between CNB and death. Survival rates were estimated with the use of the KaplanMeier method.

All $p$ values are two-sided and $p \leq 0.05$ was considered significant. Calculations were performed by the statistical software SAS@ (version 9.4, SAS Institute Inc., Cary, NC, USA).

\section{Results}

\section{Concordance of Ki67-LI and molecular subtype between CNB and SR}

Median Ki67-LI was $21.4 \%$ and $21.7 \%$ for CNB and SR, respectively. A substantial agreement of Ki67-LI between CNB and SR specimens was observed. The ROC for molecular subtype in CNB to correctly diagnose LumA in SR (Ki67-LI <20\%) resulted in an area under the curve (AUC) of 0.8333 (Fig. 1a), indicating moderate association. When applying a cutoff point of CNB Ki67-LI $<20 \%$ for LumA molecular subtype, 152 of 195 LumA cases were diagnosed correctly (sensitivity $77.95 \%$; 95\% CI 71.62-83.20\%) and 43 tumors were falsely classified as LumB by CNB. Two hundred thirty-four out of $289 \mathrm{LumB}$ cases were correctly classified as Ki67-LI $\geq 20 \%$ (specificity $80.97 \%$; 95\% CI 76.05$85.08 \%$ ), and 55 cases were falsely classified as LumA by CNB (Fig. 1b).

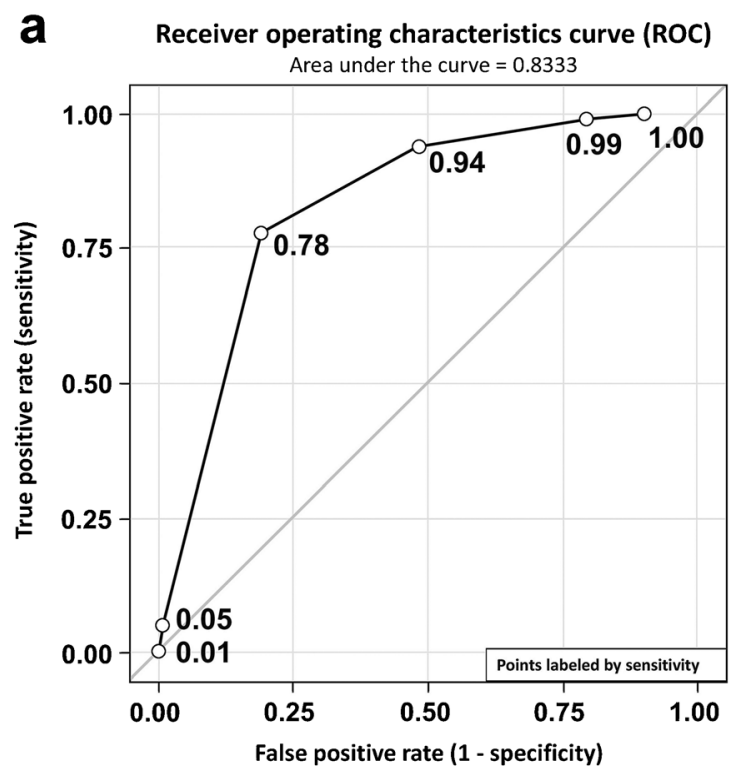

b

Fig. 1 a Receiver operating characteristics (ROC) curve for luminal IST by CNB. Numbers given are true positive rate and correspond to CNB cutoff values of $<5,<10,<20,<30,<40$, and $<50$, respectively. b Agreement of luminal IST determination in core needle biopsy (CNB)
Agreement of molecular subtype determination by Ki67-LI was observed in $386(79.8 \%)$ patients. In 98 (20.3\%) patients, Ki67-LI in CNB and SR were discordant. Examples are shown in Fig. 2.

\section{CNB-related factors influencing agreement}

In our analysis, we identified tumor grade (including all separate grading components), lower PR expression, higher p53 expression, and LVI as tumor-related factors in CNB that significantly influenced agreement of molecular subtype. A dependence between ER expression in CNB and Ki67-LI for LumA and LumB tumors could not be demonstrated, mainly due to small group sizes with ER $<80 \%$ in CNB ( 7 LumA tumors and 14 LumB tumors). Results are shown in detail in Table 2.

\section{SR-related factors influencing agreement}

In SR specimens, tumor grade (including all separate grading components), tumor size (pT), multifocality, lymph node involvement $(\mathrm{pN}), \mathrm{LVI}$, and performed mastectomy were identified as tumor-related factors that significantly influenced agreement of molecular subtype. Results are shown in detail in Table 3.

\section{Prognostic significance of molecular subtype agreement}

Survival data was available for 390 patients, of whom 177 (30\%) were correctly diagnosed with luminal A tumors and 


\section{Concordant}
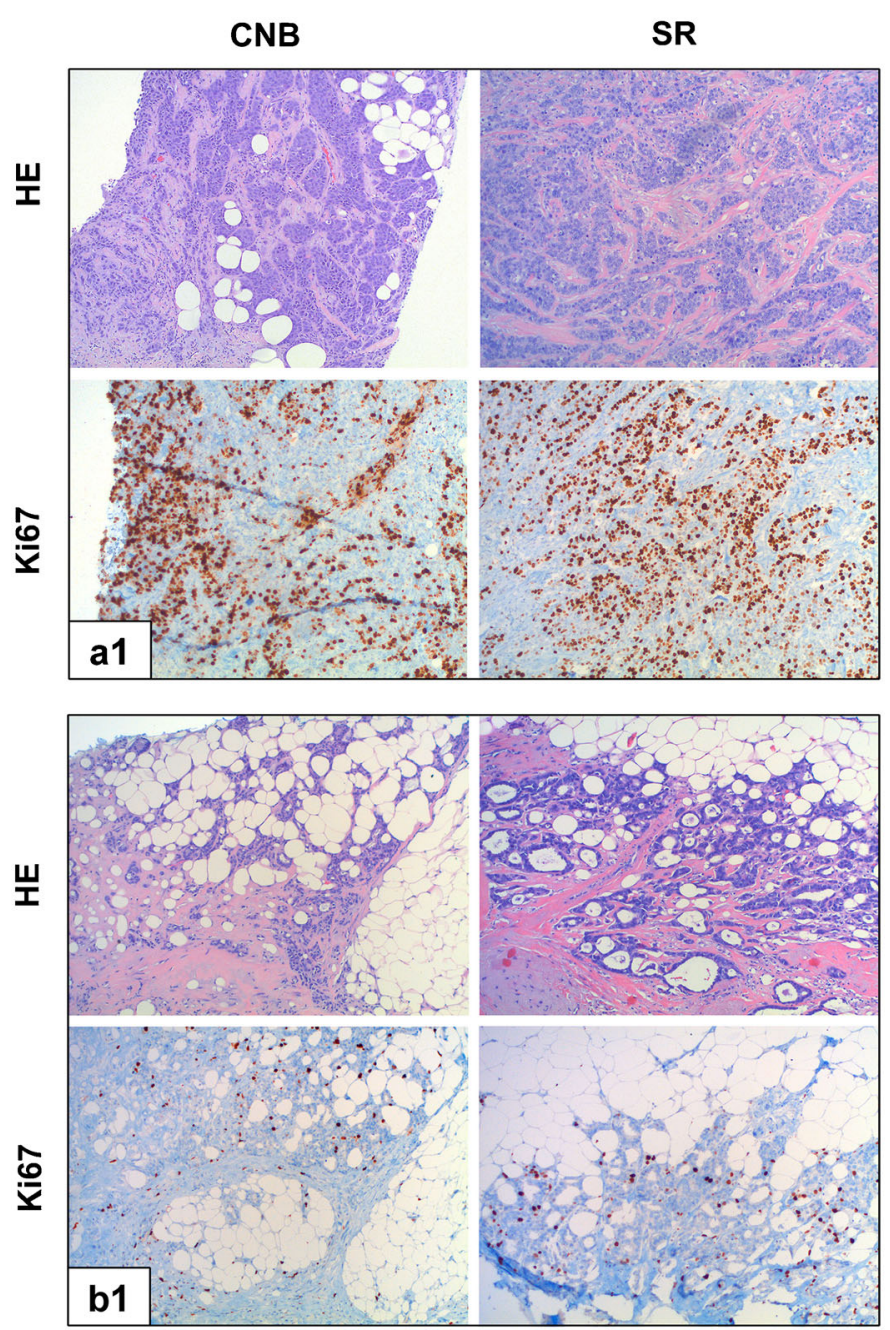

Fig. 2 Hematoxylin and eosin (HE) and Ki67-LI immunohistochemical stainings showing breast cancer cases displaying concordant and discordant luminal IST and Ki67-LI in CNB and SR, respectively $(\times 100$ magnification). a HE and respective Ki67-LI IHC slides of two patients with concordant Ki67-LI when comparing CNB and SR. A1 Ki67-LI 60\%

$199(51 \%)$ were correctly diagnosed with luminal B disease in CNB. In 43 patients (11.2\%), a LumA tumor in CNB was upgraded to LumB by SR and in 31 patients (7.9\%), a LumB tumor in CNB was downgraded to LumA by SR. Kaplan-Meier analyses revealed no significant differences regarding RFS and OS (log-rank test, $p=0.22$, respectively). However, patients with correctly diagnosed LumB tumors tended to have a worse RFS and OS, as shown in Fig. 3.

\section{Discussion}

The present study analyzed concordance of Ki67-LI between corresponding $\mathrm{CNB}$ and $\mathrm{SR}$ in $\mathrm{BC}$ with respect to defining molecular subtype. Our aim was to identify method- and tumor-related factors that influence reliability of Ki67-LI/
Discordant
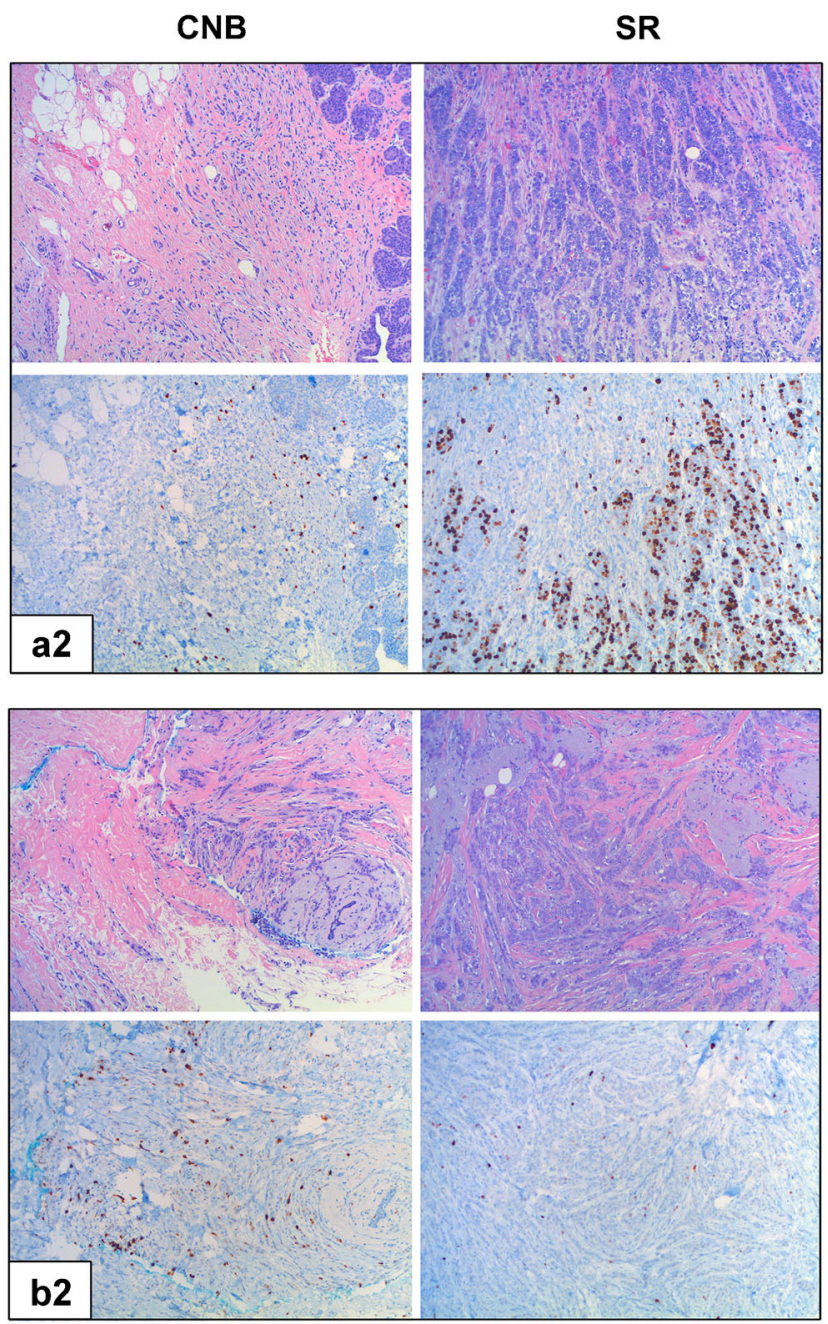

indicating LumB IST in both CNB and SR; A2 10\% Ki67 indicating LumA IST in both CNB and SR. b HE and respective Ki67 IHC slides of two patients with discordant luminal IST and Ki67-LI when comparing CNB and SR. B1 Ki67 10\% (LumA) in CNB, 30\% (LumB) in SR; B2 $20 \%$ (LumB) Ki67-LI in CNB, 5\% (LumA) in SR.

molecular subtype determination in CNB. Although smaller studies have previously been conducted [29-31], our study is distinguished by the inclusion of patients with luminal $\mathrm{BC}$ exclusively, as Ki67-LI has a therapeutic consequence only in these patients [30]. Of particular importance is the reliable identification of LumB disease in CNB, as in these patients, neoadjuvant chemotherapy is often indicated.

In our study, $79.8 \%$ of tumors were reliably classified according to molecular subtype, indicating a moderate agreement. Discrepancies in Ki67-LI between CNB and SR samples have been reported, even when no neoadjuvant systemic therapy was applied [32]. Sampling errors as well as intratumoral heterogeneity leading to a non-representative CNB have been discussed as potential confounding factors [17]. The abundance of tumor cells in SR compared with CNB can represent intratumoral heterogeneity to a higher 
Table 2 Tumor-related factors in CNB influencing agreement of luminal IST

\begin{tabular}{|c|c|c|c|c|c|c|c|c|c|}
\hline & & Intrinsic su & type $(n)$ & Specificity $(\%) *$ & $p$ value & Intrinsic sul & type $(n)$ & Sensitivity $(\%) * *$ & $p$ value \\
\hline & & $\operatorname{LumA}^{\mathrm{SR}}$ & & & & $\operatorname{LumB}^{\mathrm{SR}}$ & & & \\
\hline & & $\operatorname{LumA}^{\mathrm{CNB}}$ & $\operatorname{LumB}^{\mathrm{CNB}}$ & & & $\operatorname{LumA}^{\mathrm{CNB}}$ & $\operatorname{LumB}^{\mathrm{CNB}}$ & & \\
\hline & Total & 152 & 43 & 78.0 & & 55 & 234 & 81.0 & \\
\hline CNB-grade & G1 & 85 & 12 & 87.6 & 0.0007 & 28 & 17 & 37.8 & $<0.0001$ \\
\hline & G2 & 67 & 30 & 69.1 & & 24 & 126 & 84 & \\
\hline & G3 & 0 & 1 & 0 & & 3 & 90 & 96.8 & \\
\hline & Missing & & & & & & 1 & & \\
\hline SR-grade & G1 & 78 & 11 & - & 0.0061 & 16 & 12 & - & $<0.0001$ \\
\hline & $\mathrm{G} 2$ & 73 & 32 & & & 35 & 113 & & \\
\hline & G3 & 1 & 0 & & & 4 & 109 & & \\
\hline CNB-nuclear pleomorphy & 1 & 39 & 3 & 92.9 & 0.0066 & 11 & 6 & 35.3 & $<0.0001$ \\
\hline & 2 & 108 & 37 & 74.5 & & 43 & 164 & 79.2 & \\
\hline & 3 & 5 & 3 & 62.5 & & 1 & 64 & 98.5 & \\
\hline CNB-mitotic count & 1 & 143 & 29 & 83.1 & 0.0003 & 49 & 87 & 64.0 & $<0.0001$ \\
\hline & 2 & 8 & 11 & 42.1 & & 4 & 56 & 93.3 & \\
\hline & 3 & 1 & 1 & 50.0 & & 1 & 87 & 98.9 & \\
\hline & Missing & 0 & 2 & 0 & & 1 & 4 & 80.0 & \\
\hline CNB lymphovasc. invasion & No & 152 & 43 & 78.0 & - & 54 & 216 & 80.00 & 0.1390 \\
\hline & Yes & 0 & 0 & - & & 1 & 18 & 94.74 & \\
\hline CNB ER & $10-30 \%$ & 0 & 1 & 0 & 0.1027 & 0 & 1 & 100 & 0.3548 \\
\hline & $40-70 \%$ & 4 & 2 & 66.7 & & 1 & 12 & 92.3 & \\
\hline & $80-100 \%$ & 148 & 40 & 78.7 & & 54 & 221 & 80.3 & \\
\hline CNB PR & neg. & 22 & 7 & 75.9 & 0.7984 & 2 & 30 & 93.8 & 0.0006 \\
\hline & $10-30 \%$ & 14 & 1 & 93.3 & & 2 & 39 & 95.1 & \\
\hline & $40-70 \%$ & 37 & 12 & 75.5 & & 16 & 65 & 80.2 & \\
\hline & $80-100 \%$ & 79 & 23 & 77.5 & & 35 & 100 & 74.1 & \\
\hline CNB p53 & neg. & 148 & 40 & 78.72 & 0.0868 & 51 & 172 & 77.13 & 0.0017 \\
\hline & $10-30 \%$ & 4 & 2 & 66.67 & & 4 & 37 & 90.24 & \\
\hline & $40-60 \%$ & 0 & 0 & - & & 0 & 16 & 100 & \\
\hline & $70-100 \%$ & 0 & 1 & 0 & & 0 & 9 & 100 & \\
\hline
\end{tabular}

${ }^{*}$ Specificity is the percentage of correctly diagnosed LumA patients by CNB

** Sensitivity is the percentage of correctly diagnosed LumB patients by CNB

Missing values were ignored in statistical tests

degree. Therefore, the representativity of CNB might be questionable [29, 33, 34]. Ki67-LI in SR was more accurately mirrored by CNB than by tissue microarrays, without direct influence of CNB size on reliability [29, 33-35]. Recent studies addressing intratumoral heterogeneity demonstrated that inhomogeneous distribution of tumor proliferation within single tumors exceeded Ki67-LI variation between individual luminal-type tumors [36].

Further factors such as post-acquisition handling have been considered to be of influence as well. A prolonged time span between extraction and fixation leading to hypoxic tissue damage and in succession to apoptosis of tumor cells and degradation of the Ki67 nuclear protein might result in a lower Ki67-LI in SR samples [29, 37].
We demonstrated that the CNB method did not significantly influence reliability of molecular subtype determination, whereas MRI-guided biopsies showed the lowest concordance rates (data not shown). By evaluating the influence of the time interval between CNB and surgery, we analyzed whether wound healing processes after CNB impact local tumor proliferation. Previous studies suggested that surgery time interval might influence Ki67-LI change after CNB, longer STI leading to a higher increase in Ki67-LI [38]. In our analysis, surgery time interval did not interfere with Ki67-LI and molecular subtype concordance and reliability. However, median surgery time interval differed significantly in the two studies ( 4.5 days reported by Chen at al. vs. 25 days in this study, respectively), which provides a possible explanation for 
Table 3 Tumor-related factors in SR influencing agreement of luminal IST

\begin{tabular}{|c|c|c|c|c|c|c|c|}
\hline & & \multicolumn{2}{|c|}{ Intrinsic subtype (n) } & \multirow[t]{3}{*}{$p$ value } & \multicolumn{2}{|c|}{ Intrinsic subtype (n) } & \multirow[t]{3}{*}{$p$ value } \\
\hline & & \multicolumn{2}{|l|}{$\operatorname{LumA}^{\mathrm{SR}}$} & & \multicolumn{2}{|l|}{ LumB $^{\text {SR }}$} & \\
\hline & & $\operatorname{Lum}_{A}{ }^{\mathrm{CNB}}$ & $\operatorname{LumB}^{\mathrm{CNB}}$ & & $\operatorname{Lum}^{\mathrm{CNB}}$ & $\operatorname{LumB}^{\mathrm{CNB}}$ & \\
\hline & Total & 152 & 43 & & 55 & 234 & \\
\hline \multirow[t]{3}{*}{ SR-grade } & G1 & 78 & 11 & \multirow[t]{3}{*}{0.0061} & 16 & 12 & \multirow[t]{3}{*}{$<0.0001$} \\
\hline & G2 & 73 & 32 & & 35 & 113 & \\
\hline & G3 & 1 & 0 & & 4 & 109 & \\
\hline \multirow[t]{4}{*}{ SR-glandular differentiation } & 1 & 39 & 7 & \multirow[t]{3}{*}{0.2024} & 5 & 7 & \multirow[t]{3}{*}{0.0009} \\
\hline & 2 & 43 & 12 & & 21 & 53 & \\
\hline & 3 & 70 & 24 & & 29 & 173 & \\
\hline & Missing & 0 & 0 & - & 0 & 1 & - \\
\hline \multirow[t]{4}{*}{ SR-nuclear pleomorphy } & 1 & 34 & 4 & \multirow[t]{3}{*}{0.0137} & 5 & 4 & \multirow[t]{3}{*}{$<0.0001$} \\
\hline & 2 & 103 & 30 & & 36 & 102 & \\
\hline & 3 & 15 & 9 & & 14 & 127 & \\
\hline & Missing & 0 & 0 & - & 0 & 1 & - \\
\hline \multirow[t]{4}{*}{ SR-mitotic count } & 1 & 142 & 39 & \multirow[t]{3}{*}{0.7627} & 36 & 91 & \multirow[t]{3}{*}{$<0.000$} \\
\hline & 2 & 9 & 4 & & 14 & 53 & \\
\hline & 3 & 1 & 0 & & 5 & 89 & \\
\hline & Missing & 0 & 0 & - & 0 & 1 & - \\
\hline \multirow[t]{2}{*}{ SR pT } & pT1 & 124 & 36 & \multirow[t]{2}{*}{0.7466} & 37 & 141 & \multirow[t]{2}{*}{0.3357} \\
\hline & $\geq \mathrm{pT} 2$ & 28 & 7 & & 18 & 93 & \\
\hline \multirow[t]{3}{*}{ SR lymphovascular invasion } & no & 126 & 40 & \multirow[t]{2}{*}{0.0993} & 38 & 136 & \multirow[t]{2}{*}{0.0945} \\
\hline & Yes_-mild & 26 & 3 & & 17 & 92 & \\
\hline & $\begin{array}{l}\text { Yes- } \\
\text { severe }\end{array}$ & 0 & 0 & - & 0 & 6 & - \\
\hline \multirow[t]{3}{*}{ Multifocality } & No & 124 & 29 & \multirow[t]{3}{*}{0.0465} & 45 & 166 & \multirow[t]{2}{*}{0.1110} \\
\hline & Yes & 28 & 14 & & 10 & 67 & \\
\hline & Missing & & & & 0 & 1 & - \\
\hline \multirow[t]{5}{*}{ SR-pN } & Negative & 114 & 36 & 0.4132 & 34 & 141 & 0.7858 \\
\hline & pN1a & 29 & 6 & & 13 & 52 & \\
\hline & $\mathrm{pN} 2 \mathrm{a}$ & 2 & 0 & & 4 & 19 & \\
\hline & $\mathrm{pN} 3 \mathrm{a}$ & 4 & 1 & & 2 & 11 & \\
\hline & Missing & 3 & 0 & - & 2 & 11 & - \\
\hline Breast conserving surgery & Mastectomy & 31 & 17 & 0.0101 & 9 & 65 & 0.0809 \\
\hline & $\mathrm{BCS}$ & 121 & 26 & & 46 & 169 & \\
\hline
\end{tabular}

Missing values were ignored in statistical tests

this discrepancy: a transient rise in Ki67-LI caused by wound healing processes is likely abated after a longer STI.

In our study, further clinicopathological factors, most importantly $\mathrm{G}$ and size, PR and p53 expression influenced sensitivity and specificity of molecular subtype determination. These factors are likely indicators of intratumoral heterogeneity and might therefore predict reliability of molecular subtype assessment in CNB. Previous analyses confirmed that adverse clinicopathological factors such as high G, LVI, and high p53 expression were significantly associated with a high Shannon index regarding copy number variation of oncogenes, implicating these factors as indicators of intratumoral heterogeneity [39].
ER-negative tumors display higher concordance rates between CNB and SR than ER-positive tumors [30]. In our study, PR negativity was significantly associated with increased concordance in luminal BC. Furthermore, inferior agreement was found in G1 and G2 tumors compared with G3 tumors. We also reported a lower Ki67-LI concordance rate and lower luminal molecular subtype agreement in comparison with the distinction between luminal and non-luminal subtype [30].

We now report that additional factors, such as multifocality, PR, and p53 expression, also affect sensitivity of Ki67-LI assessment. Considering these factors is likely to increase the acuity of molecular subtype determination. 


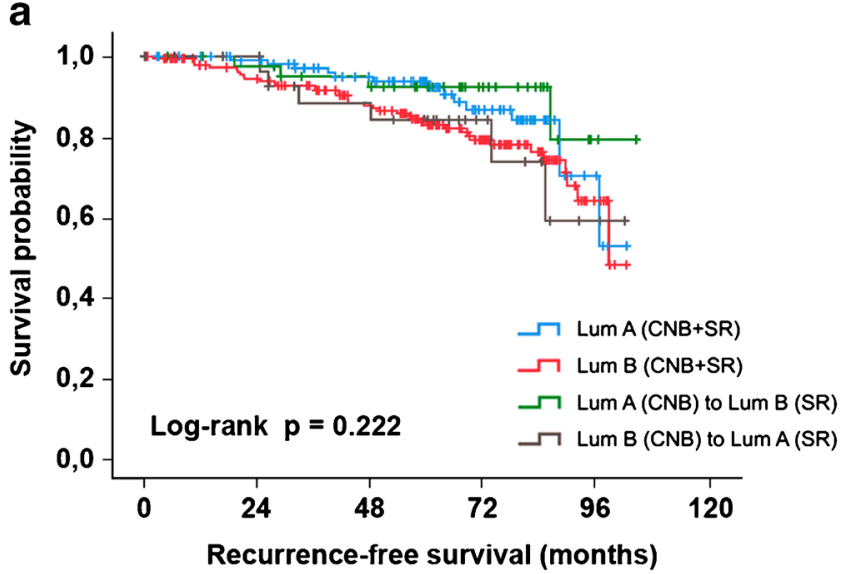

Fig. 3 Recurrence-free (a) and overall (b) survival of patients according to IST in $\mathrm{CNB} / \mathrm{SR}$. Correctly diagnosed cases included $177 \mathrm{LumA}$ tumors $(\mathrm{CNB}+\mathrm{SR})$ and $199 \mathrm{LumB}$ tumors $(\mathrm{CNB}+\mathrm{SR})$. Within the discordant

In our study, all separate grading components, namely glandular differentiation, nuclear pleomorphy, and mitotic count, inflicted a significant impact on correctly classifying luminal molecular subtype. Although applying histological grade and mitotic index might reliably identify LumA tumors, Ki67-LI is needed to correctly classify LumB tumors [40]. In our study, specificity to identify LumA tumors decreased with increasing histological grade. These findings are in line with previous studies reporting frequent underestimation of tumor grade in $\mathrm{CNB}$, whereas reliable grading showed significant association with CNB size [36].

At present, no uniform cutoff levels for Ki67-LI have been defined and discrepancies regarding thresholds and their implications for clinical decisions remain [1, 2, 17-19, 41]. Regarding this problem, an expert panel was not able to stipulate an ideal cutoff point for routine use [17]. Association of Ki67-LI values between 10 and $20 \%$ with BC outcome has been proven in a meta-analysis [42]. Inter-observer variability was most pronounced between 10 and $30 \%$ positivity, where clinically valid cutoff values are suggested [43]. The normalization to 5-percentile values and a variable cutoff may solve this problem, depending on the clinical purpose [32]. For the present study, we chose a cutoff of $\geq 20$ for LumB BC, as previously validated in a clinical trial [28].

Our study revealed no statistically significant differences in RFS and OS depending on agreement of molecular subtype between CNB and SR, which might be explained by the limited cohort size and the low number of events.

Previous studies suggested that digital image analysis vs. visual determination might improve molecular subtype determination by immunohistochemistry [44]; however, comparative studies using digital image analysis in assessing Ki67-LI in CNB and SR are scarce. In these smaller cohorts, the reported agreement between CNB and SR was comparable with

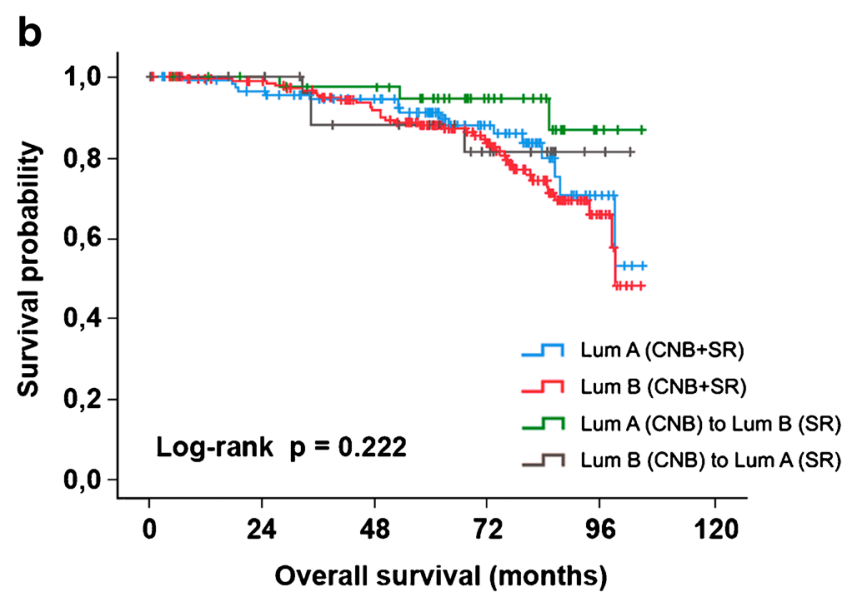

cases, 43 LumA tumors in CNB were upgraded to LumB by SR, and in $31 \mathrm{LumB}$, tumors in CNB were downgraded to LumA by SR.

our results, although digital image analysis slightly improved determination $[45,46]$. Notably, none of these studies investigated the impact of molecular subtype/Ki67-LI determination on patient survival.

In our study, pathological factors such as tumor grade, size, $\mathrm{PR}$, and p53 expression significantly influenced agreement of Ki67-LI and luminal molecular subtype between CNB and SR. These factors mirror tumor heterogeneity and can objectivize molecular subtype determination in CNB.

More importantly, our results question the robustness of a single CNB-driven measurement of Ki67 in luminal BC of low (G1) or intermediate (G2) histological grade and warrant further investigations to improve the validity of molecular subtype determination in these cases.

Authors' contributions Conceptualization: Kristina A. Tendl-Schulz, Zsuzsanna Bago-Horvath

Methodology: Kristina A. Tendl-Schulz, Fabian Rössler, Zsuzsanna Bago-Horvath

Formal analysis and investigation: Kristina A. Tendl-Schulz, Fabian Rössler, Philipp Wimmer, Ulrike M. Heber, Katja Pinker, Rupert Bartsch, Peter Dubsky, Florian Fitzal, Fanny Carolina Eckel, Eva-Maria Langthaler, Günther Steger, Michael Gnant, Christian F. Singer, Thomas H. Helbich, Zsuzsanna Bago-Horvath

Statistical analyses: Martina Mittlböck, Nicolas Kozakowski, Martin Filipits

Writing - original draft preparation: Kristina A. Tendl-Schulz, Fabian Rössler, Zsuzsanna Bago-Horvath

Writing - review and editing: Kristina A. Tendl-Schulz, Fabian Rössler, Philipp Wimmer, Ulrike M. Heber, Martina Mittlböck, Nicolas Kozakowski, Katja Pinker, Rupert Bartsch, Peter Dubsky, Florian Fitzal, Martin Filipits, Fanny Carolina Eckel, Eva-Maria Langthaler, Günther Steger, Michael Gnant, Christian F. Singer, Thomas H. Helbich, Zsuzsanna Bago-Horvath

Funding information Open access funding provided by Medical University of Vienna. Katja Pinker was in part supported by the NIH/ 
NCI Cancer Center Support Grant P30 CA008748 of Memorial Sloan Kettering Cancer Center.

Data availability The datasets generated during and/or analyzed during the current study are not publicly available due to legal personal data protection issues but are available from the corresponding author on reasonable request.

\section{Compliance with ethical standards}

Conflict of interest Kristina A. Tendl-Schulz: Dr. Tendl-Schulz reports travel support from Roche and Novartis, and lecture honoraria from Roche outside the submitted work.

Ulrike M. Heber: Dr. Heber reports travel support from Novartis, outside the submitted work.

Katja Pinker: Dr. Pinker received payment for activities not related to the present article including lectures including service on speakers bureaus and for travel/accommodations/meeting expenses unrelated to activities listed from the European Society of Breast Imaging (MRI educational course, annual scientific meeting).

Rupert Bartsch: Dr. Bartsch reports lecture honoraria from BMS, Lilly, Novartis, Roche, Pfizer, and Pierre-Fabre, advisory role for MSD, Lilly, Novartis, Roche, Pfizer, Pierre-Fabre, and Daiichi, and research support from Novartis and Roche, outside the submitted work.

Peter Dubsky: Dr. Dubsky reports grants from Cepheid/Danaher, outside the submitted work.

Florian Fitzal: Dr. Fitzal reports financial support for travel, research, and ad board: Pfizer, Astra Zeneca, MyriadMyriad, Comesa, Bondimed, Astra Zeneca, Novartis, Roche, Springer; outside the submitted work.

Martin Filipits: Dr. Filipits reports grants and personal fees from Astra Zeneca, personal fees from Bayer, personal fees from Boehringer Ingelheim, personal fees from Eli Lilly, personal fees from Merck, personal fees from MSD, personal fees from Novartis, personal fees from Ratiopharm, personal fees from Roche, and personal fees from Myriad, outside the submitted work.

Günther Steger: Dr. Steger reports honoraria and travel support from Roche, outside the submitted work.

Michael Gnant: Dr. Gnant has received institutional research support from Astra Zeneca, Roche, Novartis, and Pfizer, and has received lecture fees, honoraria for participation on advisory boards, and travel support from Amgen, Astra Zeneca, Celgene, EliLilly, Invectys, Pfizer, Nanostring, Novartis, and Roche. He has served as a consultant for Astra Zeneca and Eli Lilly, and an immediate family member is employed by Sandoz.

Thomas H. Helbich: Dr. Helbich reports educational grants and seed grants from Hologic, Novomed, and Bard.

Christian F Singer: Dr. Singer has received institutional research support from Novartis, Roche, Daiichi Sanyko, Astra Zeneca, and Pfizer, and has received honoraria, lecture fees, and travel support from Astra Zeneca, Amgen, Novartis, Roche, Pfitzer, and EliLilly.

Zsuzsanna Bago-Horvath: Dr. Bago-Horvath reports grants from Boehringer Ingelheim, personal fees and honoraria for participation on advisory boards from Novartis, Biomedica, and Roche, and travel support from Roche, outside the submitted work.

Fabian Rössler, Philipp Wimmer, Martina Mittlböck, Nicolas Kozakowski, Fanny Carolina Eckel, Eva-Maria Langthaler: no conflicts of interest.

Ethics approval The present study was granted approval by the Ethics Review Board of the Medical University of Vienna (1245/2017).

Open Access This article is licensed under a Creative Commons Attribution 4.0 International License, which permits use, sharing, adaptation, distribution and reproduction in any medium or format, as long as you give appropriate credit to the original author(s) and the source, provide a link to the Creative Commons licence, and indicate if changes were made. The images or other third party material in this article are included in the article's Creative Commons licence, unless indicated otherwise in a credit line to the material. If material is not included in the article's Creative Commons licence and your intended use is not permitted by statutory regulation or exceeds the permitted use, you will need to obtain permission directly from the copyright holder. To view a copy of this licence, visit http://creativecommons.org/licenses/by/4.0/.

\section{References}

1. Goldhirsch A, Wood WC, Coates AS, Gelber RD, Thürlimann B, Senn HJ, Panel members (2011) Strategies for subtypes - dealing with the diversity of breast cancer: highlights of the St Gallen International Expert Consensus on the Primary Therapy of Early Breast Cancer 2011. Ann Oncol 22:1736-1747. https://doi.org/10. 1093/annonc/mdr304

2. Goldhirsch A, Winer EP, Coates AS, Gelber RD, Piccart-Gebhart M, Thürlimann B, Senn HJ, Albain KS, André F, Bergh J, Bonnefoi H, Bretel-Morales D, Burstein H, Cardoso F, Castiglione-Gertsch M, Coates AS, Colleoni M, Costa A, Curigliano G, Davidson NE, di Leo A, Ejlertsen B, Forbes JF, Gelber RD, Gnant M, Goldhirsch A, Goodwin P, Goss PE, Harris JR, Hayes DF, Hudis CA, Ingle JN, Jassem J, Jiang Z, Karlsson P, Loibl S, Morrow M, Namer M, Kent Osborne C, Partridge AH, Penault-Llorca F, Perou CM, PiccartGebhart MJ, Pritchard KI, Rutgers EJT, Sedlmayer F, Semiglazov V, Shao ZM, Smith I, Thürlimann B, Toi M, Tutt A, Untch M, Viale G, Watanabe T, Wilcken N, Winer EP, Wood WC (2013) Personalizing the treatment of women with early breast cancer: highlights of the St Gallen International Expert Consensus on the Primary Therapy of Early Breast Cancer 2013. Ann Oncol 24: 2206-2223. https://doi.org/10.1093/annonc/mdt303

3. Cuzick J, Dowsett M, Pineda S, Wale C, Salter J, Quinn E, Zabaglo L, Mallon E, Green AR, Ellis IO, Howell A, Buzdar AU, Forbes JF (2011) Prognostic value of a combined estrogen receptor, progesterone receptor, $\mathrm{Ki}-67$, and human epidermal growth factor receptor 2 immunohistochemical score and comparison with the Genomic Health recurrence score in early breast cancer. J Clin Oncol 29: 4273-4278. https://doi.org/10.1200/JCO.2010.31.2835

4. Hugh J, Hanson J, Cheang MCU, Nielsen TO, Perou CM, Dumontet C, Reed J, Krajewska M, Treilleux I, Rupin M, Magherini E, Mackey J, Martin M, Vogel C (2009) Breast cancer subtypes and response to docetaxel in node-positive breast cancer: use of an immunohistochemical definition in the BCIRG 001 trial. J Clin Oncol 27:1168-1176. https://doi.org/10.1200/JCO.2008.18. 1024

5. Cheang MCU, Chia SK, Voduc D, Gao D, Leung S, Snider J, Watson M, Davies S, Bernard PS, Parker JS, Perou CM, Ellis MJ, Nielsen TO (2009) Ki67 index, HER2 status, and prognosis of patients with luminal B breast Cancer. J Natl Cancer Inst 101: 736-750. https://doi.org/10.1093/jnci/djp082

6. von Minckwitz G, Schmitt WD, Loibl S, Muller BM, Blohmer JU, Sinn BV, Eidtmann H, Eiermann W, Gerber B, Tesch H, Hilfrich J, Huober J, Fehm T, Barinoff J, Rudiger T, Erbstoesser E, Fasching PA, Karn T, Muller V, Jackisch C, Denkert C (2013) Ki67 measured after neoadjuvant chemotherapy for primary breast cancer. Clin Cancer Res 19:4521-4531. https://doi.org/10.1158/1078-0432. CCR-12-3628

7. Niikura N, Sakatani T, Arima N, Ohi Y, Honma N, Kanomata N, Yoshida K, Kadoya T, Tamaki K, Kumaki N, Iwamoto T, Sugie T, Moriya T (2016) Assessment of the Ki67 labeling index: a Japanese 
validation ring study. Breast Cancer 23(1):92-100. https://doi.org/ 10.1007/s12282-014-0536-0

8. Perou CM, Sørlie T, Eisen MB, van de Rijn M, Jeffrey SS, Rees CA, Pollack JR, Ross DT, Johnsen H, Akslen LA, Fluge Ø, Pergamenschikov A, Williams C, Zhu SX, Lønning PE, Børresen-Dale AL, Brown PO, Botstein D (2000) Molecular portraits of human breast tumours. Nature 406:747-752. https://doi. org $/ 10.1038 / 35021093$

9. Sørlie T, Tibshirani R, Parker J, Hastie T, Marron JS, Nobel A, Deng S, Johnsen H, Pesich R, Geisler S, Demeter J, Perou CM, Lønning PE, Brown PO, Børresen-Dale AL, Botstein D (2003) Repeated observation of breast tumor subtypes in independent gene expression data sets. Proc Natl Acad Sci 100:8418-8423. https:// doi.org/10.1073/pnas.0932692100

10. Criscitiello C, Disalvatore D, De Laurentiis M et al (2014) High Ki67 score is indicative of a greater benefit from adjuvant chemotherapy when added to endocrine therapy in luminal B HER 2 negative and node-positive breast cancer. Breast 23:69-75. https://doi.org/ 10.1016/j.breast.2013.11.007

11. Munzone E, Curigliano G, Colleoni M (2013) Tailoring adjuvant treatments for the individual patient with luminal breast cancer. Hematol Oncol Clin North Am 27:703-714. https://doi.org/10. 1016/j.hoc.2013.05.012

12. Horimoto Y, Arakawa A, Tanabe M, Sonoue H, Igari F, Senuma K, Tokuda E, Shimizu H, Kosaka T, Saito M (2014) Ki67 expression and the effect of neo-adjuvant chemotherapy on luminal HER2negative breast cancer. BMC Cancer 14:550. https://doi.org/10. 1186/1471-2407-14-550

13. Coates AS, Winer EP, Goldhirsch A, et al (2015) Tailoring therapies - improving the management of early breast cancer: St Gallen International Expert Consensus on the Primary Therapy of Early Breast Cancer 2015. Ann Oncol mdv221. https://doi.org/10. 1093/annonc/mdv221

14. Plancoulaine B, Laurinaviciene A, Herlin P, Besusparis J, Meskauskas R, Baltrusaityte I, Iqbal Y, Laurinavicius A (2015) A methodology for comprehensive breast cancer Ki67 labeling index with intra-tumor heterogeneity appraisal based on hexagonal tiling of digital image analysis data. Virchows Arch Int J Pathol 467:711722. https://doi.org/10.1007/s00428-015-1865-x

15. Laurinavicius A, Plancoulaine B, Rasmusson A, Besusparis J, Augulis R, Meskauskas R, Herlin P, Laurinaviciene A, Abdelhadi Muftah AA, Miligy I, Aleskandarany M, Rakha EA, Green AR, Ellis IO (2016) Bimodality of intratumor Ki67 expression is an independent prognostic factor of overall survival in patients with invasive breast carcinoma. Virchows Arch 468:493-502. https:// doi.org/10.1007/s00428-016-1907-z

16. Gándara-Cortes M, Vázquez-Boquete Á, Fernández-Rodríguez B, Viaño P, Ínsua D, Seoane-Seoane A, Gude F, Gallego R, Fraga M, Antúnez JR, Curiel T, Pérez-López E, García-Caballero T (2018) Breast cancer subtype discrimination using standardized 4-IHC and digital image analysis. Virchows Arch 472:195-203. https://doi. org/10.1007/s00428-017-2194-Z

17. Dowsett M, Nielsen TO, A'Hern R et al (2011) Assessment of Ki67 in breast cancer: recommendations from the International Ki67 in Breast Cancer Working Group. J Natl Cancer Inst 103:1656-1664. https://doi.org/10.1093/jnci/djr393

18. Gadzicki D, Schubert A, Fischer C, Milde S, Lehmann U, Steinemann D, Lück HJ, Kreipe H, Schlegelberger B (2009) Histopathological criteria and selection algorithms for BRCA1 genetic testing. Cancer Genet Cytogenet 189:105-111. https://doi. org/10.1016/j.cancergencyto.2008.11.003

19. Rody A, Karn T, Ruckhäberle E, Müller V, Gehrmann M, Solbach C, Ahr A, Gätje R, Holtrich U, Kaufmann M (2008) Gene expression of topoisomerase II alpha (TOP2A) by microarray analysis is highly prognostic in estrogen receptor (ER) positive breast cancer.
Breast Cancer Res Treat 113:457-466. https://doi.org/10.1007/ s10549-008-9964-x

20. Wallis M, Tardivon A, Tarvidon A et al (2007) Guidelines from the European Society of Breast Imaging for diagnostic interventional breast procedures. Eur Radiol 17:581-588. https://doi.org/10.1007/ s00330-006-0408-x

21. DOWNLOADS - Overview - EUREF | European Reference Organisation for Quality Assured Breast Screening and Diagnostic Services. http://www.euref.org/downloads.

22. downloads.pdf. In: Eur. Guidel. Qual. Assur. Breast Cancer Screen. Diagn. PDF. http://www.euref.org/downloads?download=24: european-guidelines-for-quality-assurance-in-breast-cancerscreening-and-diagnosis-pdf. Accessed 5 Jul 2017

23. Sobin LH, Gospodarowicz MK, Wittekind C (2009) TNM classification of malignant tumours, 7 edition. Wiley-Blackwell, Chichester, West Sussex, UK ; Hoboken, NJ

24. Elston CW, Ellis IO (1991) Pathological prognostic factors in breast cancer. I. The value of histological grade in breast cancer: experience from a large study with long-term follow-up. Histopathology 19:403-410

25. Elston CW, Ellis IO (2002) Pathological prognostic factors in breast cancer. I. The value of histological grade in breast cancer: experience from a large study with long-term follow-up. C. W. Elston \& I. O. Ellis. Histopathology 1991; 19; 403-410. Histopathology 41: 151-151. https://doi.org/10.1046/j.1365-2559.2002.14691.x

26. Hammond MEH, Hayes DF, Dowsett M, Allred DC, Hagerty KL, Badve S, Fitzgibbons PL, Francis G, Goldstein NS, Hayes M, Hicks DG, Lester S, Love R, Mangu PB, McShane L, Miller K, Osborne CK, Paik S, Perlmutter J, Rhodes A, Sasano H, Schwartz JN, Sweep FC, Taube S, Torlakovic EE, Valenstein P, Viale G, Visscher D, Wheeler T, Williams RB, Wittliff JL, Wolff AC, American Society of Clinical Oncology, College of American Pathologists (2010) American Society of Clinical Oncology/ College of American Pathologists guideline recommendations for immunohistochemical testing of estrogen and progesterone receptors in breast cancer (unabridged version). Arch Pathol Lab Med 134:e48-e72. https://doi.org/10.1043/1543-2165-134.7.e48

27. Wolff AC, Hammond MEH, Hicks DG, Dowsett M, McShane LM, Allison KH, Allred DC, Bartlett JMS, Bilous M, Fitzgibbons P, Hanna W, Jenkins RB, Mangu PB, Paik S, Perez EA, Press MF, Spears PA, Vance GH, Viale G, Hayes DF (2013) Recommendations for human epidermal growth factor receptor 2 testing in breast cancer: American Society of Clinical Oncology/ College of American Pathologists clinical practice guideline update. J Clin Oncol Off J Am Soc Clin Oncol 31:3997-4013. https://doi. org/10.1200/JCO.2013.50.9984

28. Bago-Horvath Z, Rudas M, Dubsky P, Jakesz R, Singer CF, Kemmerling R, Greil R, Jelen A, Bohm G, Jasarevic Z, Haid A, Gruber C, Postlberger S, Filipits M, Gnant M, for the Austrian Breast and Colorectal Cancer Study Group (2011) Adjuvant sequencing of tamoxifen and anastrozole is superior to tamoxifen alone in postmenopausal women with low proliferating breast cancer. Clin Cancer Res 17:7828-7834. https://doi.org/10.1158/10780432.CCR-11-1846

29. Romero Q, Bendahl P-O, Klintman M, Loman N, Ingvar C, Rydén L, Rose C, Grabau D, Borgquist S (2011) Ki67 proliferation in core biopsies versus surgical samples-a model for neo-adjuvant breast cancer studies. BMC Cancer 11:341. https://doi.org/10.1186/14712407-11-341

30. Chen X, Sun L, Mao Y, Zhu S, Wu J, Huang O, Li Y, Chen W, Wang J, Yuan Y, Fei X, Jin X, Shen K (2013) Preoperative core needle biopsy is accurate in determining molecular subtypes in invasive breast cancer. BMC Cancer 13:390. https://doi.org/10. 1186/1471-2407-13-390

31. Ricci MD, Filho C, Cabral CM et al (2012) Analysis of the concordance rates between core needle biopsy and surgical excision in 
patients with breast cancer. Rev Assoc Médica Bras 58:532-536. https://doi.org/10.1590/S0104-42302012000500008

32. Cserni G, Vörös A, Liepniece-Karele I, Bianchi S, Vezzosi V, Grabau D, Sapino A, Castellano I, Regitnig P, Foschini MP, Zolota V, Varga Z, Figueiredo P, Decker T, Focke C, Kulka J, Kaya H, Reiner-Concin A, Amendoeira I, Callagy G, Caffrey E, Wesseling J, Wells C (2014) Distribution pattern of the Ki67 labelling index in breast cancer and its implications for choosing cut-off values. Breast 23:259-263. https://doi.org/10.1016/j.breast.2014. 02.003

33. Cassano E, Urban LABD, Pizzamiglio M, Abbate F, Maisonneuve P, Renne G, Viale G, Bellomi M (2006) Ultrasound-guided vacuum-assisted core breast biopsy: experience with 406 cases. Breast Cancer Res Treat 102:103-110. https://doi.org/10.1007/s10549006-9305-x

34. Di Nubila B, Cassano E, Urban LABD et al (2006) Radiological features and pathological-biological correlations in 348 women with breast cancer under 35 years old. Breast 15:744-753. https:// doi.org/10.1016/j.breast.2006.02.006

35. Focke CM, Decker T, van Diest PJ (2017) Reliability of the Ki67labelling index in core needle biopsies of luminal breast cancers is unaffected by biopsy volume. Ann Surg Oncol 24:1251-1257. https://doi.org/10.1245/s10434-016-5730-1

36. Focke CM, Decker T, van Diest PJ (2016) Intratumoral heterogeneity of Ki67 expression in early breast cancers exceeds variability between individual tumours. Histopathology 69:849-861. https:// doi.org/10.1111/his.13007

37. Rakha EA, Ellis IO (2007) An overview of assessment of prognostic and predictive factors in breast cancer needle core biopsy specimens. J Clin Pathol 60:1300-1306. https://doi.org/10.1136/jcp. 2006.045377

38. Chen X, Zhu S, Fei X, Garfield DH, Wu J, Huang O, Li Y, Zhu L, He J, Chen W, Jin X, Shen K (2015) Surgery time interval and molecular subtype may influence Ki67 change after core needle biopsy in breast cancer patients. BMC Cancer 15:822. https://doi. org/10.1186/s12885-015-1853-1

39. Chung YR, Kim HJ, Kim YA, et al (2017) Diversity index as a novel prognostic factor in breast cancer. Oncotarget 8:97114 97126. https://doi.org/10.18632/oncotarget.21371
40. Oddó D, Pulgar D, Elgueta N, et al (2018) Can histological grade and mitotic index replace Ki67 to determine luminal breast cancer subtypes? Asian Pac J Cancer Prev APJCP 19:179-183. https://doi. org/10.22034/APJCP.2018.19.1.179

41. Alfarsi L, Johnston S, Liu D-X, Rakha E, Green AR (2018) Current issues with luminal subtype classification in terms of prediction of benefit from endocrine therapy in early breast cancer. Histopathology 73:545-558. https://doi.org/10.1111/his.13523

42. Stuart-Harris R, Caldas C, Pinder SE, Pharoah P (2008) Proliferation markers and survival in early breast cancer: a systematic review and meta-analysis of 85 studies in 32,825 patients. Breast 17:323-334. https://doi.org/10.1016/j.breast.2008.02.002

43. Varga Z, Diebold J, Dommann-Scherrer C, Frick H, Kaup D, Noske A, Obermann E, Ohlschlegel C, Padberg B, Rakozy C, Sancho Oliver S, Schobinger-Clement S, Schreiber-Facklam H, Singer G, Tapia C, Wagner U, Mastropasqua MG, Viale G, Lehr HA (2012) How reliable is Ki-67 immunohistochemistry in grade 2 breast carcinomas? A QA study of the Swiss Working Group of Breast- and Gynecopathologists. PLoS One 7:e37379. https://doi.org/10.1371/ journal.pone.0037379

44. Stålhammar G, Robertson S, Wedlund L, Lippert M, Rantalainen M, Bergh J, Hartman J (2018) Digital image analysis of Ki67 in hot spots is superior to both manual Ki67 and mitotic counts in breast cancer. Histopathology 72:974-989. https://doi.org/10.1111/his. 13452

45. Ahn S, Lee J, Cho M-S, Park S, Sung SH (2018) Evaluation of Ki67 index in core needle biopsies and matched breast cancer surgical specimens. Arch Pathol Lab Med 142:364-368. https://doi.org/10. 5858/arpa.2017-0014-OA

46. Jeong YS, Kang J, Lee J, Yoo TK, Kim SH, Lee A (2020) Analysis of the molecular subtypes of preoperative core needle biopsy and surgical specimens in invasive breast cancer. J Pathol Transl Med 54:87-94. https://doi.org/10.4132/jptm.2019.10.14

Publisher's note Springer Nature remains neutral with regard to jurisdictional claims in published maps and institutional affiliations. 